\title{
Additional Surgery for New Tumor Event Absent
}

National Cancer Institute

\section{Source}

National Cancer Institute. Additional Surgery for New Tumor Event Absent. NCI

Thesaurus. Code C160300.

Additional surgery for the new tumor event was not performed. 